\title{
Characterization of $\mathrm{KNb}_{3} \mathrm{O}_{8}$ Powders by Raman Spectroscopy and Scanning Electron Microscopy
}

Francisco Rojas Gonzalez ${ }^{1}$, Ofelia Hernandez Negrete ${ }^{1}$, Hilda Esparza Ponce ${ }^{2}$, Roberto Duarte Zamorano $^{1}$, Roberto Carrillo Torres ${ }^{1}$ and Javier Hernandez Paredes ${ }^{1}$

${ }^{1}$ Universidad de Sonora, Hermosillo, Sonora, Mexico, ${ }^{2}$ Centro de Investigacion en Materiales Avanzados S.C., Chihuahua, Chihuahua, Mexico

Potassium Triniobate $\mathrm{KNb}_{3} \mathrm{O}_{8}$ is an inorganic material that has promising photocatalytic applications for removing pollutants from wastewater [1]. Although there are different approaches to obtain this material, solid-state reactions at high temperature are used for obtaining powders of $\mathrm{KNb}_{3} \mathrm{O}_{8}$ [2]. Herein, we report the synthesis of $\mathrm{KNb}_{3} \mathrm{O}_{8}$ powders by solid-state reaction at $800^{\circ} \mathrm{C}$ for $3 \mathrm{~h}$ of $\mathrm{Nb}_{2} \mathrm{O}_{5}$ and $\mathrm{KCl}$.

$0.26581 \mathrm{~g}$ ( $1 \mathrm{mmol})$ of $\mathrm{Nb}_{2} \mathrm{O} 5$ (99.5\%, Alfa Aesar, USA), $0.3727 \mathrm{~g}$ (5 mmol) of $\mathrm{KCl}(99.0 \%$ SigmaAldrich, México) and $100 \mu \mathrm{L}$ of deionised water were mixed to form. The paste was ground in an agate mortar for $20 \mathrm{~min}$. Then, the powders were placed in a conventional furnace and heated at $800^{\circ} \mathrm{C}$ for $3 \mathrm{~h}$. The powders were structurally characterised through Raman spectroscopy using a HORIBA Scientific LabRAM HR spectrometer integrated with laser light of $632 \mathrm{~nm}$ and by Field Emission Scanning Electron Microscopy (FESEM) within the JEOL JSM-7800F microscope.

Figure 1 shows the Raman spectrum of the powders. The peak maxima correspond to the vibrational modes of the $\mathrm{KNb}_{3} \mathrm{O}_{8}$ phase and are in good agreement with the literature [3]. This characteristic confirmed that after the solid-state reaction at $800^{\circ} \mathrm{C}$ for three hours, the $\mathrm{KNb}_{3} \mathrm{O}_{8}$ phase was obtained.

The elemental X-ray mapping in Figure 2 shows a homogeneous composition of the $\mathrm{KNb}_{3} \mathrm{O}_{8}$ compound obtained after calcination. The SEC image shows the microstructure of the sample, which consists of particles with different morphologies; flake-like and needle-like. The flake-like particles were coarser than the needle-like particles which seem to be formed as a result of breakage of the flake-like particles. The needles are approximately $150 \mathrm{~nm} \times 1-3 \mu \mathrm{m}$. The thickness of the flakes is between $50-100 \mathrm{~nm}$.

The method described here produced $\mathrm{KNb}_{3} \mathrm{O}_{8}$ powders at $800^{\circ} \mathrm{C}$ for 3 hours. Apparently, the grinding process allowed a homogeneous distribution of the elements, which favours the diffusion of $\mathrm{K}$ into the lattice of $\mathrm{Nb}_{2} \mathrm{O}_{5}$ to yield $\mathrm{KNb}_{3} \mathrm{O}_{8}$. This result opens the possibility to explore the synthesis of other systems through this methodology [4]. 


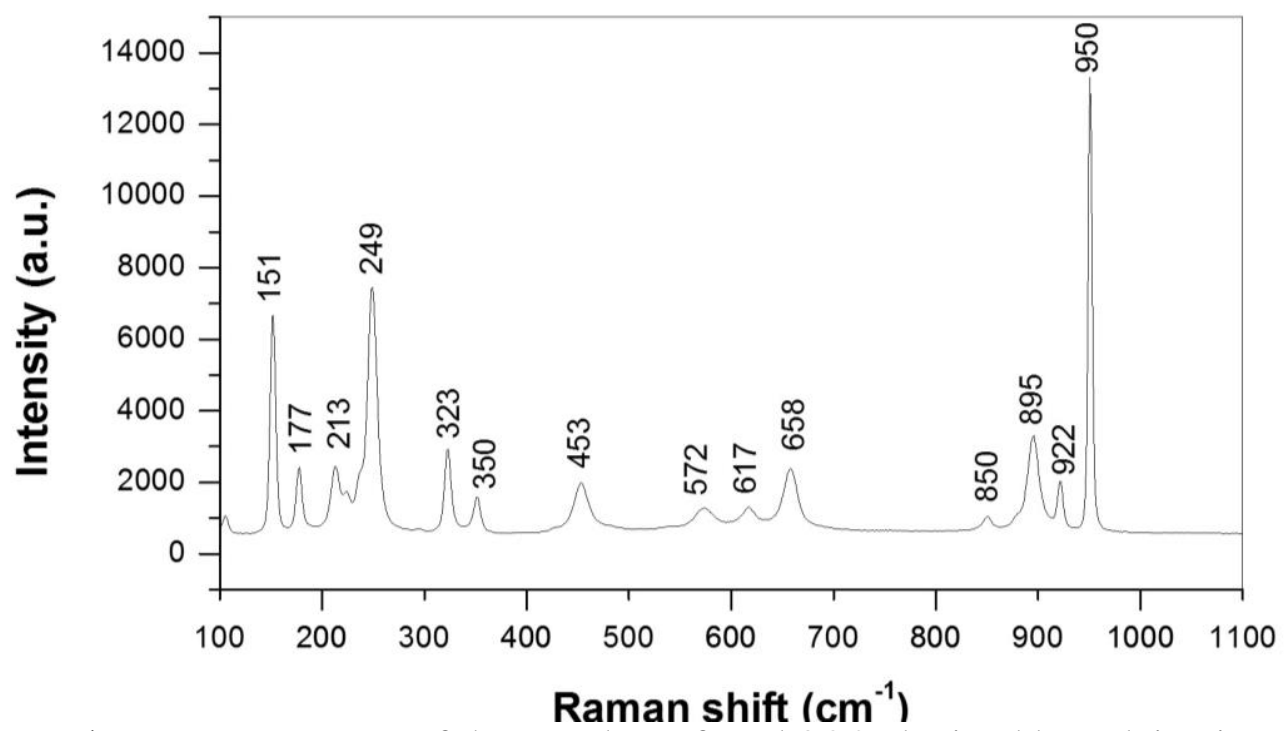

Figure 1. Raman spectrum of the powders of $\mathrm{KNb} 3 \mathrm{O} 8$ obtained by calcination at $800^{\circ} \mathrm{C}$ for 3 hours.

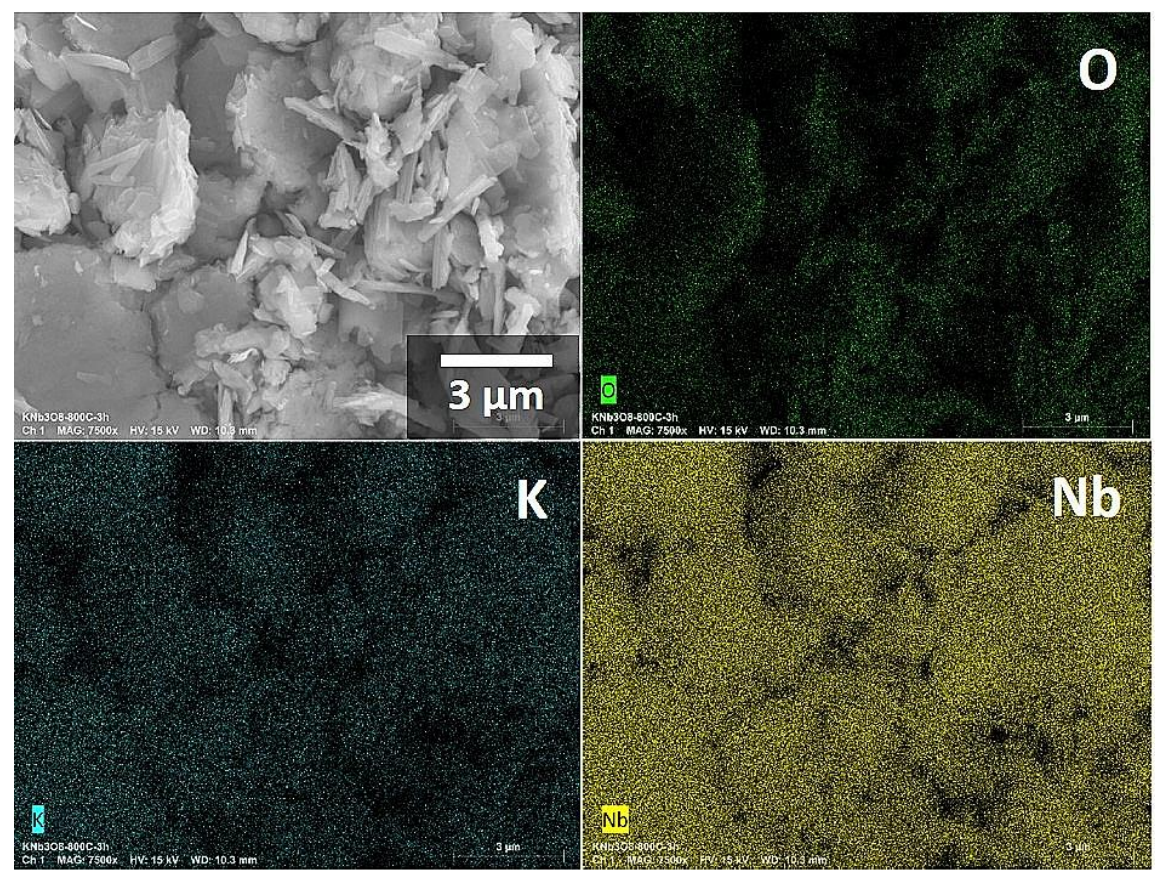

Figure 2. SEM image and elemental mapping of the powders of $\mathrm{KNb} 3 \mathrm{O} 8$ obtained by calcination at $800^{\circ} \mathrm{C}$ for 3 hours.

\section{References}

[1] S. Susuki, et al., CrystEngComm, 14 (2012) p. 987.

[2] L. Nunes, et al., J. Alloys Compd. 319 (2001) p. 94.

[3] R. Li, et al. Appl. Surf. Sci., 439 (2018) p. 986.

[4] The authors acknowledge funding from PRODEP-México through project 511-6/18-8537. F. RojasGonzález gratefully acknowledge the scholarship provided by CONACyT (México). The authors thank Department of Physics of Universidad de Sonora for allowing access to laboratories and facilities. 